\title{
Long-term follow-up of red-filter treatment of amblyopia
}

\author{
S. R. K. MALIK, P. SINGH, AND B. K. GOEL
}

From the Department of Ophthalmology, Maulana Azad Medical College, and the Associated Irwin and G. B. Pant Hospitals, New Delhi, India

The purpose of this article is to present our experiences with red-filter treatment and to re-evaluate our earlier cases (Malik, Gupta, Choudry, and Sen, I968; Malik, Gupta, and Choudry, rg6ga,b). This is a convenient and simple method, as the patient does not need to come to the clinic daily for treatment. The amblyopic eye is occluded (non-conventional occlusion) most of the time, so that the patient can continue his daily work without any handicap. The healthy eye is occluded only for short periods when the patient is using the red filter.

\section{Methods and material}

The cases were selected from the amblyopia and squint clinic of Irwin Hospital, New Delhi. A detailed history was elicited, and a thorough ophthalmic examination made. Fixation was determined by Keeler's Projectoscope with a Linksz Star graticule (Malik and others, 1969a).

A series of 55 patients with amblyopia and eccentric fixation was given red-filter treatment for 2 to 75 weeks (average $16 \cdot 5$ ). Their ages ranged from 5 to 42 years (average $15 \cdot 4$ ). The amblyopic eye was occluded during waking hours except when the patient was required to read with the red filter in front of the amblyopic eye and the healthy eye occluded. Each word was spelt out, so that the patient had to observe each letter with concentration. The size of the letters was progressively reduced and the treatment times gradually increased from 30 minutes to 4 hours.

Visual acuity was determined by the ability to read a whole line of Snellen's Optotypes. A gain of one line and a shift of fixation towards the fovea were taken as the criteria of improvement.

Of the 55 cases, fifteen were followed up for 12 to 49 months after the cessation of treatment.

\section{Observations}

\section{(A) OVERALL IMPROVEMENT}

Vision or fixation or both improved in $3^{1}$ cases ( $5^{6}$ per cent.); in nineteen cases improvement occurred in both vision and fixation, in four in vision only, and in eight in fixation only (Fig. I).

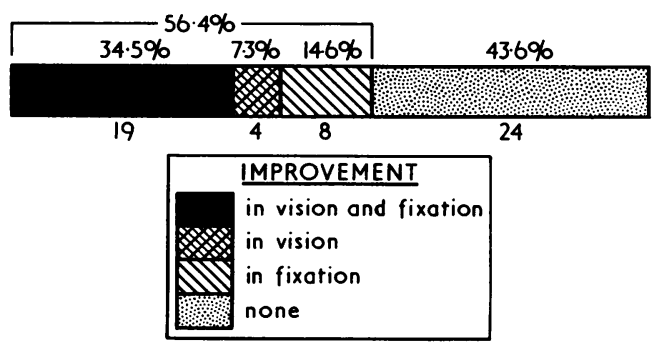

FIG. I Improvement in 3 I cases 
Improvement in visual acuity is shown in Table I. A total of 23 cases (4 per cent.) showed some improvement: good in eleven ( 20 per cent.), fair in ten ( 8 per cent.), and poor in two (4 per cent.). Patients who had a gross degree of amblyopia showed less improvement than the others, but this difference was not statistically significant $\left(\chi^{2}=\right.$ 0.9 for one degree of freedom; $\mathrm{P}>0.30$ ).

Table I Improvement in visual acuity

\begin{tabular}{|c|c|c|c|c|c|c|c|c|c|c|}
\hline Visual acuity & Final & $<6 / 60$ & $6 / 6 o$ & $6 / 36$ & $6 / 24$ & $6 / 18$ & $6 / 12$ & $6 / 9$ & $6 / 6$ & Total \\
\hline \multirow{7}{*}{ Initial } & $<6 / 60$ & $1 I^{*}$ & 2 & I & - & - & - & - & - & 14 \\
\hline & $6 / 60$ & - & $6^{*}$ & 3 & I & I & - & - & - & II \\
\hline & $6 / 36$ & - & - & $6^{*}$ & 2 & 2 & 3 & - & - & 13 \\
\hline & $6 / 24$ & - & - & - & $5^{*}$ & - & - & 2 & I & 8 \\
\hline & $6 / 18$ & - & - & - & - & $4^{*}$ & - & I & - & 5 \\
\hline & $6 / 12$ & - & - & - & - & - & - & $\ldots$ & 2 & 2 \\
\hline & $6 / 9$ & - & - & - & - & - & - & - & 2 & 2 \\
\hline Total cases & & I I & 8 & Io & 8 & 7 & 3 & 3 & 5 & 55 \\
\hline
\end{tabular}

*Not improved

Improvement in fixation is shown in Table II. 27 cases (49 per cent.) showed some improvement, foveal fixation being achieved in eighteen ( 3 per cent.). Patients with a gross degree of eccentric fixation improved less than the others; this difference was statistically significant $\left(\chi^{2}=5 \cdot 5\right.$ for one degree of freedom; $\left.\mathrm{P}<0 \cdot 02\right)$.

Table II Improvement in fixation

\begin{tabular}{|c|c|c|c|c|c|c|c|c|c|}
\hline Fixation & Final & Divergent & Paracaecal & Centrocaecal & Paramacular & Parafoveal & Erratic & Foveal & Total \\
\hline \multirow[t]{6}{*}{ Initial } & Divergent & $I^{*}$ & $\cdots$ & - & - & - & - & - & 1 \\
\hline & Paracaecal & - & $9^{*}$ & I & I & I & - & - & 12 \\
\hline & Centrocaecal & - & - & $2^{*}$ & - & - & - & - & 2 \\
\hline & Paramacular & - & - & -- & $6^{*}$ & 4 & - & 5 & 15 \\
\hline & Parafoveal & 一 & - & - & - & $8^{*}$ & 2 & 9 & 19 \\
\hline & Erratic & $\cdots$ & - & - & - & - & $2^{*}$ & 4 & 6 \\
\hline \multicolumn{2}{|c|}{ Total cases } & $\mathrm{I}$ & 9 & 3 & 7 & I3 & 4 & 18 & 55 \\
\hline
\end{tabular}

*Not improved

Fig. 2 shows the improvement in different age groups and Fig. 3 relates the improvement to age at onset, Fig. 4 to family history, and Fig. 5 to the refractive error of the amblyopic eye. None of these relationships was statistically significant.

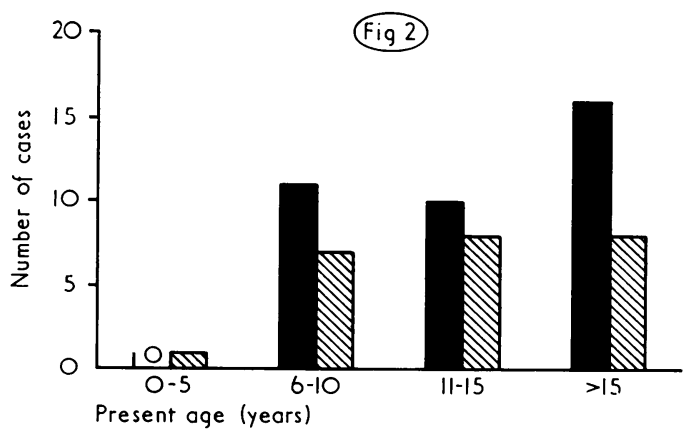

FIG. 2 Improvement by age group

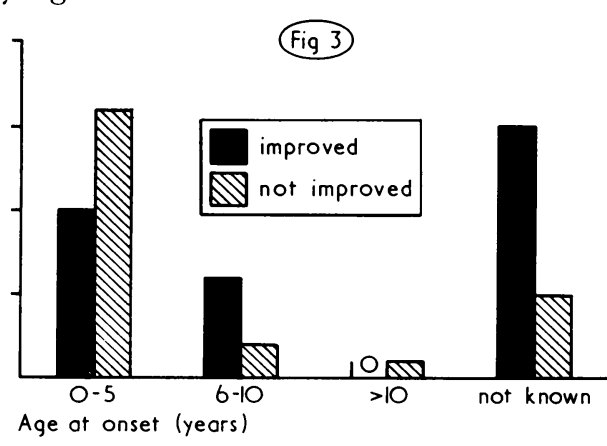

FIG. 3 Improvement by age at onset 

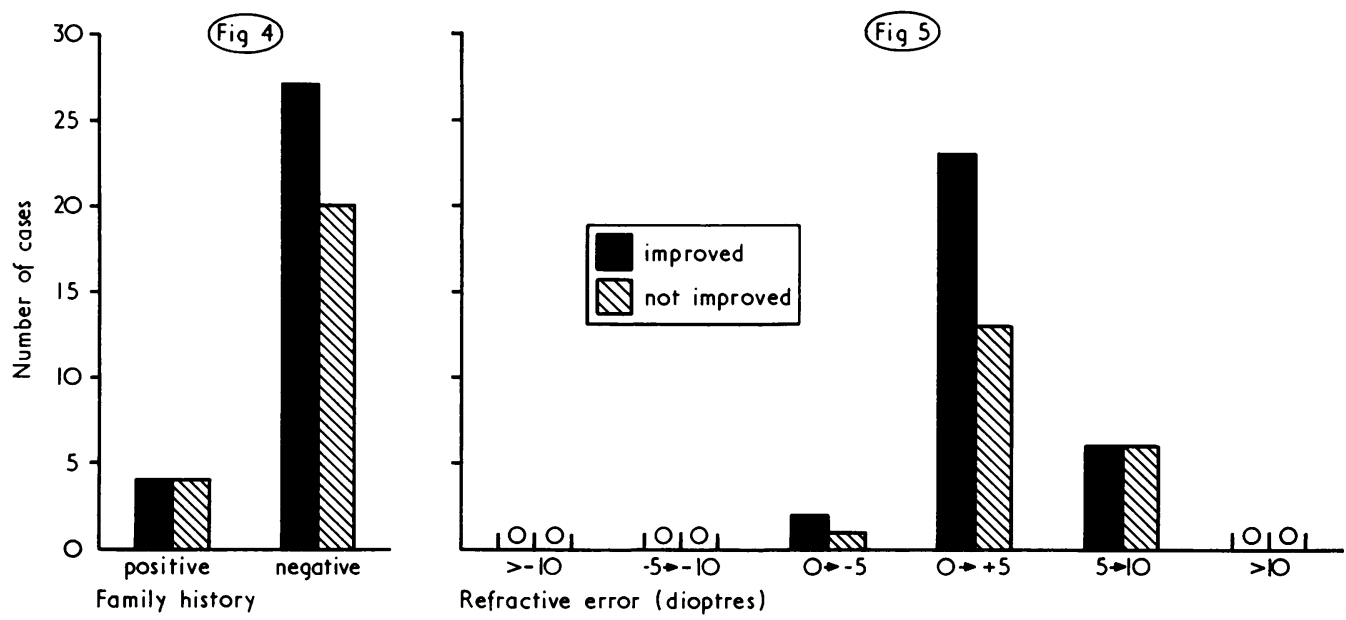

FIG. 4 Improvement related to family history

FIG. 5 Improvement related to refractive error

(B) LONG-TERM FOLLOW-UP

The ages of the fifteen patients followed-up for an average of 21 months varied from 6 to 35 years (average I4). Five maintained and five partially maintained the improvement, but five deteriorated to the pretreatment level. The levels of visual acuity and fixation are shown in Fig. 6.
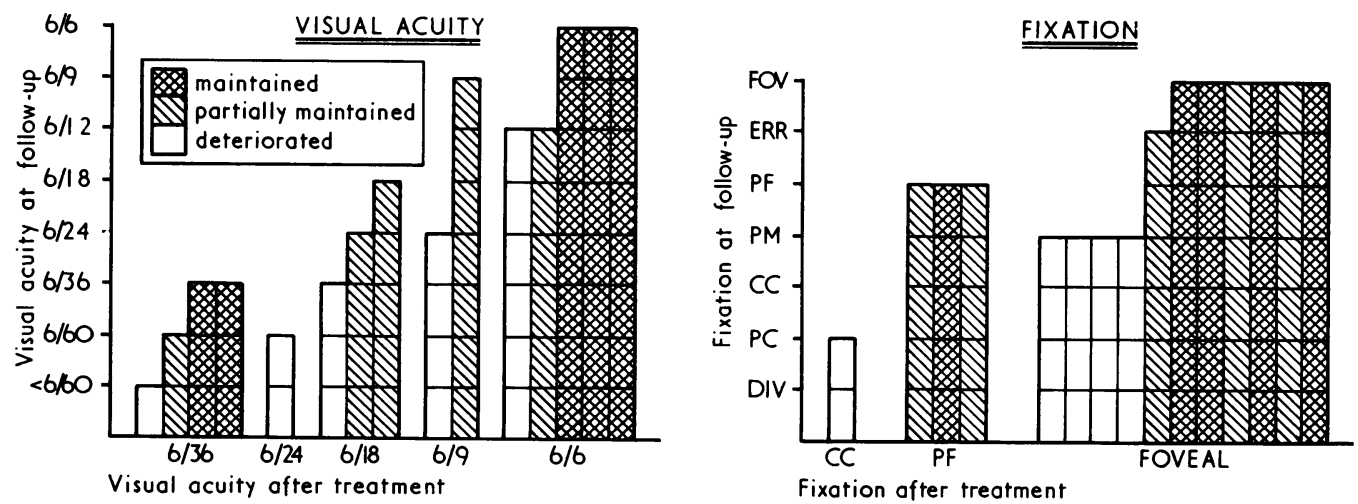

FIG. 6 Maintenance of visual acuity and fixation after treatment

The age of the patient, state of binocularity, degree of anisometropia, and refractive error were found to have no bearing on the maintenance of results. As was to be expected, however, deterioration occurred more often in those who did not follow the instructions given to them, for the use of glasses and orthoptic exercises (Table III, overleaf).

\section{Discussion}

The results of the present study (improvement in 56 per cent.) are slightly better than those of our previous studies (Malik and others, I968; 1969a,b) in which improvement was found in 47 and 44 per cent. respectively. A retrospective investigation showed that the difference is due to the fact that some of those with gross amblyopia achieved a better result. This may be attributed to our more recent methods of patient care. 
Table III Relationship between the results and patients' adherence to instructions

\begin{tabular}{llllll}
\hline $\begin{array}{l}\text { Exercises or glasses } \\
\text { used after treatment }\end{array}$ & $\begin{array}{l}\text { No. of } \\
\text { patients }\end{array}$ & & $\begin{array}{l}\text { Results } \\
\text { Maintained }\end{array}$ & Partly maintained & Deteriorated \\
\cline { 5 - 6 } & & & 5 & 5 & 3 \\
Yes & 2 & & - & - & 2 \\
\hline Total & I5 & 5 & 5 & 5 \\
\hline
\end{tabular}

The difference in results is statistically significant $\left(\chi^{2}=4.62\right.$ with Yates correction: $\chi^{2}:==I \cdot(30$ without Yates correction).

It was found that those who were severely affected found the red filter tiresome and did not persevere with it. We are now calling these patients regularly to our clinic so that treatment can be in our presence. To start with they are given bigger print with wider spacing and have to spell each word, following each letter with the finger. This helps to maintain interest and build up confidence. Gross amblyopia requires much more attention and motivation before any improvement can be expected, and even then the standard attained is lower than in patients who are less severely affected.

Slightly better results were obtained in patients over 15 years of age because of better co-operation during treatment, but this difference was not statistically significant. Our finding that the age at onset of amblyopia was not related to the outcome of therapy agrees with the findings of Flynn and Vereecken ( 1967 ). In our cases family history seemed to be unimportant but Flynn and Vereecken (1967) found better results in patients with a negative family history.

It was found that the only factor which had any significant influence on the maintenance of improvement was whether the patient followed the post-treatment instructions or not; those who did not use glasses or attend for orthoptic exercises as advised, were those who showed significant deterioration. This demonstrates that patients who improve with therapy should be followed up at monthly intervals for the first 6 months and then every 6 months for 2 years, and that any deterioration should be dealt with by total or partial conventional occlusion.

\section{Summary}

Of 55 patients with varying degrees of amblyopia who were given red-filter treatment, 56 per cent. showed improvement. The factors influencing the results are discussed and a comparison is made with our previous studies.

I am grateful to Mr. Baljit Singh, orthoptist, Department of Ophthalmology, Maulana Azad Medical College, and Associated Irwin and G. B. Pant Hospitals, for technical assistance.

\section{References}

FLYNN, J. T., and VEREECKEN, E. (1967) Brit. 7. Ophthal., 51, 804 MALIK, s. R. L., GUPTA, A. K., and CHOUDRY, s. (I969a) Ibid., 53, I 88

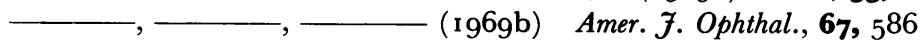

$-\longrightarrow,-$, , $\longrightarrow$ and sen, D. K. (1968) Brit. J. Ophthal., 52, 839 